\title{
REGULAÇÃO ESTATAL VERSUS CULTURA DE AVALIAÇÃO INSTITUCIONAL?
}

\author{
VALDEMAR Sguissardi* \\ * Licenciado em Filosofia (Unijuí), Mestre e Doutor em Ciências da Educação (Universidade de Paris X \\ - Nanterre, Fr); Professor Titular aposentado da UFSCar e Titular da Unimep; Pesquisador de Políticas \\ Públicas de educação superior, com diversos livros e artigos publicados sobre este tema. E-mail: vs@ \\ merconet.com.br
}

Resumo: Este texto visa problematizar a relação entre regulação e controle estatal com avaliação que privilegie a criação e implementação da cultura de avaliação e auto-avaliação institucional. Para tanto, examinam-se a natureza do Estado e da regulação estatal, a concepção de educação superior predominante no seu modelo de expansão, além dos obstáculos para essa relação próprios das IES estatais públicas e privado/mercantis.

Palavras-chave: Educação superior. Regulação. Cultura de avaliação.

\section{STATE REGULATION VERSUS INSTITUTIONAL EVALUATION CULTURE?}

\begin{abstract}
This work seeks to discuss the relation between regulation and state control with evaluation that privileges the creation and implementation of evaluation and institutional self-evaluation cultures. In order to do so, the nature of the state and of state regulation, the predominant idea of higher education in its model of expansion and the obstacles to this relation are examined.
\end{abstract}

Key words: Higher Education. Regulation. Evaluation culture.

O modelo de expansão da educação superior que se verifica no Brasil, a exemplo ou de modo similar ao que ocorre em diferentes países do centro e da periferia, põe, entre outras questões, a da relação entre regulação estatal e cultura de avaliação institucional.

Para identificar essa relação e os problemas dela decorrentes para a qualidade do sistema de educação superior, necessita-se caracterizar, ainda que sumariamente, esse modelo de expansão e as contradições do Estado, assim como verificar o que se entende por regulação e o que pressupõe a existência de uma cultura de avaliação e auto-avaliação nas instituições de educação superior (IES).

A criação recente, pelo $\mathrm{MEC}$, do Conceito Preliminar de Cursos $-\mathrm{CPC}^{1}$ e do Índice Geral de Cursos das Instituições de Educação Superior - $\mathrm{IGC}^{2}$ é apenas um exemplo de certo modelo de regulação que contradiria frontalmente um

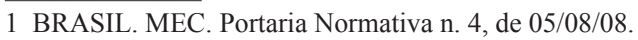

2 BRASIL. MEC. Portaria Normativa n. 12, de 05/09/08. 
dos objetivos básicos do Sistema Nacional de Avaliação da Educação Superior - SINAES ${ }^{3}$, isto é, o gradativa implementação da cultura de avaliação nas IES. O ranking das IES do país - que decorre da aplicação do IGC - divulgado "com festa" pela grande mídia poucos dias após a criação deste índice, está sendo visto por muitos especialistas que ajudaram a elaborar e implantar o SINAES como sua mais completa negação.

Dir-se-ia que o neopragmatismo típico do mundo econômico, que se caracteriza pela supervalorização da competitividade mercantil, tomou conta do sistema de supervisão e regulação estatal da educação superior no Brasil, pretextando uma suposta avaliação de sua qualidade.

Como explicar essa aparente contradição num Estado, tido como razoavelmente democrático e administrado por um governo eleito que empunhou a bandeira da expansão e fortalecimento da educação superior estatal pública e da regulação e controle do sistema, com especial atenção para o seu setor privado/mercantil?

Para responder a esta questão, inicia-se por caracterizar o modelo de expansão do sistema desde, por exemplo, o início do Governo FHC, 1995, véspera da aprovação da Lei de Diretrizes e Bases da Educação Nacional - LDBEN 4 , até o ano $2005^{5}$. Neste período, marcam a evolução/involução dos dados da expansão das Instituições Federais de Educação Superior (IFES), entre outros, os seguintes números percentuais (aproximados): $30 \%$ de aumento na matrícula na graduação e $100 \%$ na pós-graduação stricto sensu; $10 \%$ de aumento do corpo docente; redução de $40 \%$ do corpo técnico-administrativo; redução salarial de $30 \%$ do corpo docente; redução de $30 \%$ do montante de recursos do Tesouro para manutenção IFES e de 35\% nos recursos para pessoal; aumento de $35 \%$ na relação docente/alunos, se multiplicado o montante de alunos de pós-graduação stricto sensu pelo fator de correção 4 . O principal mecanismo a frear a expansão da educação superior pública tem sido a redução do financiamento. Do ponto de vista legal um bom exemplo da política de restrição da expansão educação superior pública foram os vetos presidenciais às metas, para o setor, do Plano Nacional de Educação - PNE aprovado pelo Congresso Nacional (Lei 10.172, de 09/01/2001).

Enfatize-se que a expansão do número de IES federais, de seus campi e de suas matrículas (as vagas do vestibular de 2009 das IFES dobrará o número de 2003: 113 mil para 227 mil), dar-se-á também à custa de uma grande inten-

3 BRASIL. Lei n. 10.861, de 14/04/04.

4 BRASIL. Lei n. 9.394, de 20/12/96.

5 Dados do Censo de Educação Superior do MEC/Inep e de recente estudo de Sguissardi e Silva Jr. (2008, p. 41 et passim). 
sificação e precarização do trabalho dos docentes, que se agrava em relação ao já verificado no período anterior (SGUISSARDI; SILVA JR., 2008). Esse aumento de vagas nas IFES, que decorre da criação de uma dezena de novas universidades e multiplicação dos campi das já existentes, mas principalmente com o $\mathrm{REUNI}^{6}$, não prevê um crescimento proporcional do quadro docente (com este Programa, prevê-se um aumento de cerca de 50\% das matrículas nas IFES e de apenas $25 \%$, do número de professores). A relação professor/aluno que já era em 2005 de cerca de 1/16 tenderá a ultrapassar facilmente a própria meta inicial do REUNI, que era de 1/18. E isto sem contar com a expansão das matrículas do setor com a educação a distância e com a multiplicação das universidades tecnológicas.

Porém, o grande eixo da expansão do sistema, no período, dá-se pela via da privatização, mais propriamente, da mercadorização. Oficialmente, acolheramse as teses, veiculadas pelo Banco Mundial: em 1986, de que o retorno individual e social dos recursos públicos investidos em educação superior era muito inferior ao dos investidos na educação básica; em 1994, de que a universidade de ensino e não a universidade de pesquisa ou conhecimento era a ideal para países em desenvolvimento; e, em 1998, de que a educação superior tinha muitas das características de um bem antes privado que público. Além de ter sido adotado o princípio, disseminado também pelo Banco, em 1994, da ampliação da diferenciação institucional, da diversificação de fontes de manutenção e da participação da iniciativa privada na oferta da educação superior.

Abriram-se, no Brasil, desde 1995, todas as possibilidades legais para a expansão da educação superior privada, a começar pela LDBEN, e, principalmente, mediante o Decreto n. 2.306, de 19/08/97, da mercadorização desse nível de educação. O seu artigo $7^{\circ}$ prevê e, portanto, autoriza a existência de "Instituições privadas de ensino classificadas como particulares, em sentido estrito, com finalidade lucrativa [...]."

Para ilustrar o vertiginoso crescimento das IES privadas no Brasil, mormente das privadas com fins lucrativos (mercantis), observem-se os números que seguem:

No período de 1996 a 2004, as IES privadas passaram de 711 a 1.789 (aumento de $151 \%$ ); as matrículas passaram de 1.333 .102 a 2.985 .405 (aumento de $163 \%$ ). O percentual das matrículas públicas no total que era de $39,4 \%$ em 1996 reduziu-se a $28,3 \%$ em 2004; inversamente, o das matrículas privadas passou de $60,6 \%$ para $71,7 \%$.

6 Programa de Apoio a Planos de Reestruturação e Expansão das Universidades Federais - instituído mediante o Decreto n. 6.096, de 24 de abril de 2007. 
Quanto à mercadorização do sistema, isto é, à expansão do setor privado/mercantil, considerado o período 1999-2006, para o que existem dados no MEC/Inep ${ }^{7}$, verifica-se que, em 1999, das 1.097 IES do país, 192 eram públicas, 379 privadas e 526 privado/mercantis (48\% do total); em 2006, das 2.270 IES do país, 248 eram públicas, 439 privadas e 1.583 privado/mercantis ( $70 \%$ do total geral e 78,3\% das privadas). O crescimento das IES do país no período foi de $107 \%$; o das públicas, $29 \%$; o das privadas, $16 \%$; e o das privado/mercantis, $200 \%$...

Quanto às matrículas, a evolução no período foi: a) em 1999, de um total de $2.369 .945,832.022$ eram públicas $(35 \%)$; 886.561 eram privadas $(37,4 \%)$; e 651.362 eram privado/mercantis (27,6\%); b) em 2006, de um total de 4.676.646, 1.209.304 eram públicas $(25,8 \%) ; 1.543 .176$ eram privadas (33\%); e 1.924 .166 eram privado/mercantis $(41,2 \%)$. O crescimento das matrículas no país no período foi de $97,3 \%$; o das matrículas públicas, de $45 \%$; o das matrículas privadas, de $74 \%$; e das matrículas privado/mercantis, de $195 \% \ldots$

Sabe-se que o Estado moderno não é uma entidade a pairar acima dos interesses gerais ou das classes sociais, mas, sim, uma construção social, espaço de contradição entre os interesses públicos e privados e/ou privado/mercantis, funcionando sob a hegemonia ora destes, ora daqueles.

É no contexto de um Estado semipúblico ou semiprivado que se dá o processo de regulação, que, segundo Roger Dale, "designa, neste contexto, as actividades de controlo, isto é, de definição do enquadramento para o fornecimento dos serviços educativos, que o Estado assume através de políticas e sanções legais." (Apud ANTUNES, 2007, p. 7).

O maior avanço na definição de padrões e regras, em que devem atuar as instituições, e de sua regulação e controle deu-se com a edição do Decreto $\mathrm{n}$. 5.773, de 09/05/06. Este "Dispõe sobre o exercício das funções de regulação, supervisão e avaliação de instituições de educação superior e cursos superiores de graduação e seqüenciais no sistema federal de ensino" e teria no SINAES e no modelo Capes de avaliação seu principal ponto de apoio.

As medidas de regulação e controle tendem a entrar em contradição com os procedimentos entendidos como de avaliação institucional, que se assentam em especial na autonomia da cultura de avaliação, que não tem sido uma característica do sistema de educação superior no país ao longo da história, nem no setor público, muito menos no setor privado e/ou privado/mercantil.

7 Nos dados do Censo da Educação Superior do INEP, a separação das IES privadas (sem fins lucrativos) e particulares (privadas com fins lucrativos) para o País dá-se apenas a partir de 1999. 
Uma série de obstáculos se põe para a conciliação dos objetivos da regulação e da avaliação institucional no Brasil, entre os quais, sucintamente podem ser arrolados os que seguem:

A separação em nível federal das "agências de regulação" da graduação e da pós-graduação - INEP e CAPES. Ainda que a chamada avaliação institucional, coordenada pelo INEP, possa incluir os resultados do modelo Capes de avaliação, a diferença de modelos de avaliação, sob importantes aspectos, tende a distorcer os resultados finais. Não só, contribui, também e de forma incisiva, para aprofundar o fosso existente entre a universidade de ensino, que se realiza na graduação, e a universidade de pesquisa ou do conhecimento, que se realiza na pós-graduação.

O modelo Capes de avaliação, que, por suas características, tende a incentivar a competição entre os programas de uma mesma área, a substituir a autonomia pela heteronomia e a conduzir à conformidade. Este modelo de avaliação não contribui minimamente para criar a chamada cultura de avaliação, que deveria ser um traço marcante das IES, na perspectiva do aperfeiçoamento contínuo da qualidade do cumprimento de suas funções, que não se restringem à competição e empregabilidade.

A concepção da educação superior, burocraticamente como bem público, mas, na prática, como bem de serviço privado, e o modelo de expansão que privilegia sua oferta por empresas privado/mercantis. A própria dependência das IES públicas em relação ao Estado pelo viés do financiamento, dada a ausência de efetiva autonomia de gestão financeira das IFES, por exemplo, apesar de isto facilitar a regulação e o controle, ao mesmo tempo é a origem de problemas para a autonomia e para a cultura da avaliação e da auto-avaliação dessas instituições.

O mais problemático, porém, é a necessidade de conciliar a regulação, isto é, o reconhecimento de padrões, a acreditação de títulos, pelo Estado, de instituições que fazem do lucro seu principal, embora muitas vezes oculto, objetivo final. O livre mercado já demonstrou, nas crises passadas do capitalismo e especialmente na atual, o de que é capaz. A "mão livre do mercado" é uma boa anedota para disfarçar os objetivos reais do mercado livre, que não são nem a preservação ambiental, nem as dignas condições de trabalho dos trabalhadores, nem a qualidade dos produtos, nem a ética na prestação dos serviços e, em última instância, o bem universal da sociedade. Se isso é válido para o mercado em geral, que dizer do mercado educacional? Este apresentaria as condições mínimas - dever-se-ia dizer, ideais - para a criação e implementação da cultura da avaliação e auto-avaliação nas IES, com o agravante de um 
modelo de regulação e controle que torna público o resultado desta atividade mediante índices que produzem rankings institucionais de pertinência mais do que duvidosa?

Do exposto, pode-se concluir que a relação entre regulação estatal e cultura de avaliação institucional é problemática sob múltiplos aspectos que decorrem: da natureza do Estado (se predominantemente público ou privado/mercantil); da concepção de educação superior (se um direito e bem público ou um serviço e bem privado/mercantil); do modelo de expansão da educação superior (predominantemente pela via do estatal público ou do privado/mercantil); da natureza da regulação e do controle (se privilegia a competição, a eficiência e eficácia típica do mercado); finalmente, da questionável conciliação entre regulação e controle estatal e avaliação que privilegie a cultura de avaliação e auto-avaliação institucional.

\section{Referências}

ANTUNES, Fátima. O espaço europeu de ensino superior para uma nova ordem educacional.C ETD - Educação Temática Digital , Campinas, v. 9, n. esp., p. 1-28, dez. 2007 - ISSN: 1676-2592.6. Disponível em: $<$ http://143.106.58.55/revista/viewissue.php?id=28> Acesso em: 02 out. 2008.

SGUISSARDI, Valdemar; SILVA Jr., João dos Reis. Intensificação e precarização do trabalho nas IFES: centralidade da pós-graduação e produtivismo acadêmico. Piracicaba; São Carlos, SP, ago. 2008. (Relatório de Pesquisa - FAPESP; CNPq).

WORLD BANK. Financing education in developing countries - An exploration of policy options. Washington, DC: The World Bank, 1986.

WORLD BANK. Higher education: the lessons of experience. Washington, DC: The World Bank Group, 1994. (Series Development in Practice).

WORLD BANK. The financing and management of higher education $-\mathrm{A}$ status report on worldwide reforms. Elaborado por D. Bruce Johnstone, com colaboração de Alka Arora e William Experton. Washington, DC: The World Bank, 1998. 